\title{
Fast breeder reactors: can we
}

\section{learn from experience?}

\section{Otto Keck*}

INITIALLY, developing the fast breeder reactor (FBR) carried the promise of a virtually inexhaustible source of electricity at competitive cost. Now, three decades and substantial amounts of public expenditure later, we are not much closer to the fulfillment of that promise. Economic evaluations have consistently proved too optimistic. The commercial use of FBRs has been pushed back year after year. This experience gives little comfort to policymakers who have to decide about the next steps in FBR demonstration and commercialization.

Can we identify the sources of overoptimism and improve future policymaking? A close examination of the West German FBR programme, drawing on interviews with about 40 participants and the documents of government advisory bodies, shows a way to bring more realism into policy decisions ${ }^{1}$. The findings suggest that governments can redress the optimistic bias by requiring reactor manufacturers and utilities to make an increased contribution to the cost of the programme from their own funds. In particular, construction of a commercial-size demonstration plant should be made contingent on the utilities' willingness to finance it from their own funds. Does this proposal take due account of the potential long-term benefits to be expected from the FBR? An economic analysis of FBRs suggests that the answer is yes.

\section{Precarious beginning}

In West Germany, the development of the FBR began late compared with other countries. The principle of nuclear breeding was discovered in the 1940s, during the United States' effort to develop the atomic bomb. In 1951, a small American FBR produced the first nuclear electricity. By that time the Soviet Union and Great Britain had started on their own programmes.

The initiative for the West German programme came from the Karlsruhe nuclear research centre, a laboratory founded in 1956 with the objective of constructing and operating the research reactor FR2. Although industry contributed about half the construction costs of the reactor, the laboratory was basically

*The author is affiliated with the University of Uim, West Germany. This article was written while he was a Cierman Kennedy Memorial Fellow at the Center for Science and International Affairs as Harvard University. it expresses his International Airairs ar Harvard Universily. $t$ expresses his personal views and does not necessarily refect the views of any of the organizations or individuals involved in the West (icrma FBR progranme. a government organization. When the design of the FR2 reactor was nearing completion, the Karlsruhe scientists looked for new tasks. New work was particularly urgent for the nearly 100 scientists and engineers in the technical division, who faced lay-off after completion of the FR2 reactor. The scientists' interest focused on the FBR and a project group was established in April 1960. programme the benefits of Euratom money without taking away domestic control. Similar contracts were made in support of the French programme begun in the late 1950s, and of the Italian programme, for which the Euratom contract served as a primer. For the Karlsruhe team, the association implied authorization of an expenditure of DM 185 million (£16.6 million), extending the

The experience of the West German fast breeder reactor programme suggests ways of bringing more realism into governmental decisions on the development of new reactor types. In particular, reactor manufacturers and utilities should finance commercial-size demonstration plants from their own funds.

A preliminary programme for three years costing DM 25 million ( $£ 2.1$ million at 1960 exchange rates) was endorsed towards the end of 1960 by an advisory committee of the then Ministry for Atomic Energy. When presenting its plans, the Karlsruhe team referred to American and British forecasts that FBRs would assume a significant commercial role soon after 1970. But the advisory committee by implication rejected these forecasts when it stated explicitly that work on FBRs might be terminated after the preliminary three year programme. This cool reception came mainly from committee members with industrial backgrounds. Ministry officials were very much in favour of the project and the DM 25 million was only a fraction of what the ministry was prepared to spend for a rapid expansion of the Karlsruhe laboratory.

\section{Boost from Euratom}

The threat of possible termination did not worry the fledgeling Karlsruhe project for long. Coincident with the advisory committee's cool appraisal, the European Atomic Energy Community (Euratom) began to show interest in FBRs. The community had been founded in 1958 by Belgium, France, West Germany, Italy, Luxembourg and the Netherlands. It had little success in associating itself with national programmes for first-generation nuclear power plants (light-water reactors [LWRs] and gas-graphite reactors). To secure a useful function, Euratom committed its considerable funds to exotic technological niches, such as the organiccooled reactor, and to advanced designs, such as FBRs.

In 1963 the West German government signed an association contract with Euratom that gave the German FBR project up to 1967. Euratom was to contribute 40 per cent of these funds. This commitment made FBRs the main objective of the Karlsruhe laboratory and gave this reactor type the first priority in the West German reactor programme. In the period 1956-67 - before the first commercial orders for LWRs were placed - FBRs received more government support than any other reactor type.

This shift in priority was made without a fresh consideration of the economic need. For the Karlsruhe project, the Euratom association was a matter of survival. The Ministry for Atomic Energy was motivated mainly by the political aim to secure a fair return from West Germany's contributions to Euratom. In favour of this, it ignored the earlier cool appraisal of the FBR by its advisory committee.

\section{Prototype design}

In September 1964, the Karlsruhe team was shocked by the announcement by General Electric (US) that the company would offer a commercial FBR as early as 1974. The scientists felt that the West German programme must be pushed ahead as fast as possible to meet this competitive threat. They therefore proposed that work should start immediately on the detailed design of a 200-300 megawatt prototype plant two years earlier than previously planned.

At that time, the laboratory was working on two different versions of the FBR - one using sodium as coolant, the other steam. As a choice between the two seemed difficult, the scientists proposed designing and building one prototype plant of each type. The Ministry for Scientific Research, successor to the Ministry for Atomic Energy, awarded design contracts in November 1966 to two industrial consortia. It allocated DM 57.5 million 
( $\$ 5.1$ million) for industrial work on the sodium-cooled prototype and DM 38.7 million ( $£ 3.5$ million) for the steam-cooled prototype.

Apart from the threat of international competition, Karlsruhe's justification for accelerating the programme rested on estimates of electricity costs suggesting that, in the 1970s, FBRs would produce electricity for 15 per cent less than LWRs. The advisory committees did not discuss either argument explicitly. Implicitly the arguments were rejected when reactor manufacturers and utilities declined to make a contribution to the programme from their own funds, arguing that the economic use of FBRs was not foreseeable. Nevertheless, the ministry adopted the Karlsruhe estimates.

\section{Termination of steam breeder}

At the end of 1967, the industrial team working on the steam-cooled prototype discovered technical problems that prevented conversion of a small boilingwater reactor into a facility for testing FBR fuel elements. When plans for a 50 megawatt steam-cooled FBR in the United States were dropped in 1968, the ministry acknowledged that the ensuing lack of an information exchange with foreign programmes would increase the risks and costs of its own programme. It therefore decided in 1969 to abandon the steamcooled FBR.

At first, the firms involved opposed termination. However, the ministry got their consent by asking them either to finance part of the further development costs or to agree to the termination. The firms preferred to spend their money on other projects.

\section{SNR-300}

The economic assessment of FBRs reached a turning point in West Germany when contracts for the 300 megawatt sodiumcooled prototype plant SNR-300 were negotiated. Quotes for construction cost were four times more than earlier estimates (excluding inflation). Fuel fabrication costs were quoted as about ten times the previous estimates for commercial FBRs. This ruled out any possibility of FBRs undercutting the electricity costs of LWRs as long as uranium from low-cost reserves was available.

A new economic assessment by an advisory committee concluded that global low-cost uranium reserves might be depleted around the year 2000 , so that FBRs would not be needed before the 1990s. Probably two demonstration plants would have to be built after SNR-300 to bridge the gap to commercialization.

Postponement of the SNR-300 might have saved money by shortening this gap. However, changes in the schedule were difficult because the programme had acquired institutional momentum. A large proportion of the Karlsruhe laboratory as well of supplier firms was engaged on the FBR. If the teams were to be kept together, construction of the SNR-300 had to start within a relatively short time.

Construction began in 1973 with only two years delay against an earlier schedule. Belgium and the Netherlands participated in the project, each contributing a 15-per cent share. In 1973, the SNR-300 was

West German FBR SNR-300 at Kalkar

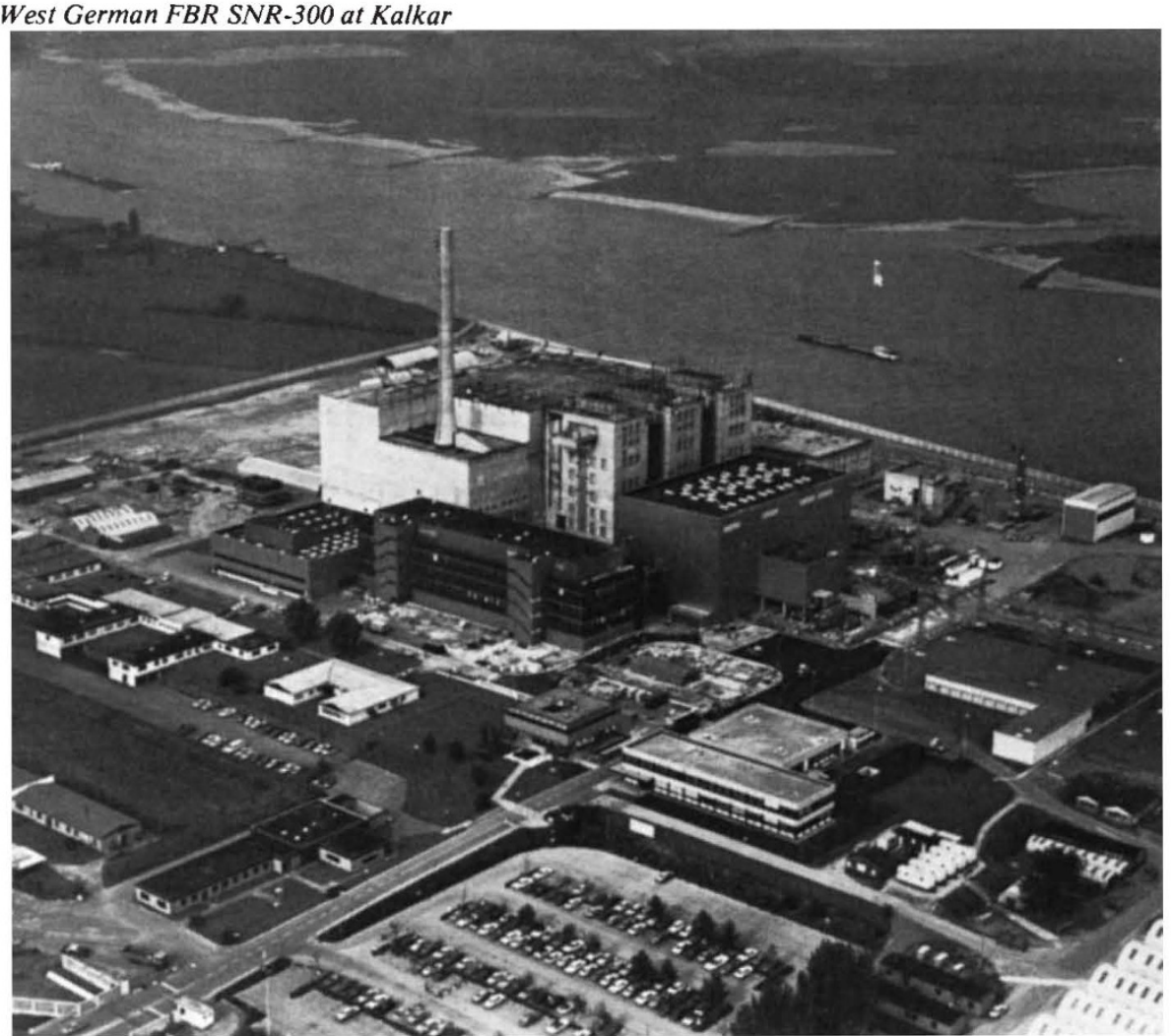

reckoned to cost DM 1,335 million ( $£ 205$ million), excluding the plutonium fuel. Operation was planned to begin in 1978 . Since then, costs have more than doubled (in constant prices). The latest estimate as of February 1981 gives a figure of DM 5,000 million ( $£ 1,050$ million). Completion is now expected in 1986.

Nearly all the funding for the project has been and is being provided by the three governments. The utilities contribute about 8 per cent of the construction cost from their own funds. West German manufacturing firms finance 8 per cent of the related research and development they perform. The total cost of industrial research and development for the SNR-300, which is not included in the above figures, is estimated at DM 350 million ( $£ 75$ million). Recently, the German utility participating in the project promised to contribute an additional DM 31 million both in 1981 and 1982, and the German reactor manufacturer pledged an amount of DM 10 million in each of these years. Even so, the firms' contributions to the overall project cost will still be less than 10 per cent. The governments also pay for all research and development performed in government laboratories. For West Germany, this implies an additional estimated expenditure of DM 950 million ( 200 million) over the period 1973-82.

\section{Lessons}

The West German experience suggests that government laboratories and agencies are ill equipped for economic assessments. As they are remote from the commercial world, they may misread the information provided by industry or the technical literature. Organizational needs or political considerations often conflict with a realistic economic evaluation - and when they do, government organizations are tempted to opt for the former.

Reactor vendors and utilities have consistently made more realistic economic assessments than the governmental participants. Yet only at the outset did representatives of industry in the advisory committees volunteer their scepticism, and even that was prompted by the general dispute on the division of responsibilities between government laboratories and industry. Later, firms revealed their scepticism only when asked to contribute some of their own funds. Then they did so implicitly rather than explicitly, revealing it only to the extent that was necessary to defend the limits on their willingness to put up their own money.

As long as only government money is at stake, industrial participants in joint projects seem to have little incentive for a sober review and frank exposure of commercial and technical uncertainties. Criticizing economic assessments made by other organizations is unpleasant. Firms do not wish to exclude themselves from a government-financed programme by questioning the government's economic 
justification. Indeed, they want to be part of the programme to know what is going on and to get some of the business.

These conclusions support the proposal ${ }^{2}$ that the construction of commercial-size demonstration plants should be contingent on the willingness of utilities to finance the costs from their own funds. A nearcommercial framework should be applied that would require reactor manufacturers to back cost estimates by guarantees with respect to performance and cost, hence making them participate in the technical and commerical risks. Although there is a case for a greater role of government in the earlier phases of a development programme, at the demonstration stage government support should be restricted to the sharing of operating risks and to the financing of background work performed by government laboratories.

Whether demonstration plants are financed through taxes or utility bills, in the end the citizen will have to defray the cost. But the government is likely to get more realistic advice if it asks utilities whether they are prepared to charge the full cost to their customers' electricity bills.

\section{Long-term benefits}

Against this proposal it may be argued that the FBR may become an indispensable source of energy at some time in the future that is further away than the short-term calculations of utilities can accommodate. A demonstration plant has to be constructed soon, the argument goes, if we are to have the capability of constructing a larger number of FBRs ten to twenty years from now, when there may be a need to do so because of the depletion of uranium resources. A study by the Organisation for Economic Cooperation and Development (OECD) and the International Atomic Energy Agency (IAEA) estimates that at a cost up to $\$ 130$ per kilogramme there are about 5 million tonnes of uranium available in the non-communist world (reasonably assured and estimated additional resources). According to the growth projections for nuclear power by the International Nuclear Fuel Cycle Evaluation (INFCE), this may not satisfy demand beyond the year 2010 .

But such calculations do not justify paying the penalties involved in constructing a FBR demonstration plant that is more expensive than what a utility would be willing to pay. Uranium prospecting and exploration have a very short history, and vast areas remain to be investigated. On the basis of indirect indications and of geological extrapolations, another study by OECD and IAEA has suggested that an additional 7-15 million tonnes of uranium deposits may be discovered with existing exploration techniques. These may carry nuclear power to the middle of the next century, if a modest growth of nuclear power is assumed.

Past projections of uranium supply and demand have proved an unreliable basis for

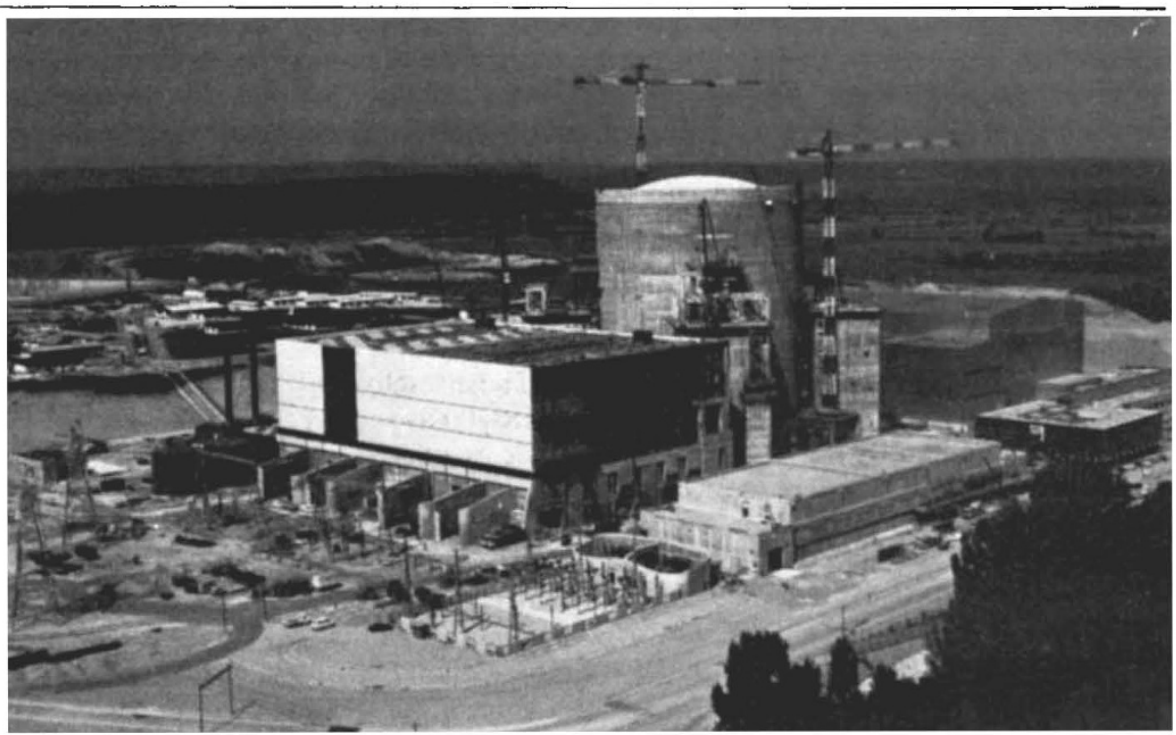

French FBR “Super-Phénix”' at Creys Malville

policy decisions. Forecasts of future nuclear capacities have steadily been downrated, while estimates of uranium resources have continuously been increased. The lower of two growth projections for nuclear power published by INFCE appears unrealistic only one year later. We do not know how long this trend will continue. The nuclear industry in most countries is presently more concerned about its survival over the short term than about the long-term supply of uranium.

Given the large uncertainties in the longterm demand for uranium and the usual conservativism in resource estimates, there is no assurance that depletion of low-cost uranium resources will necessitate the use of FBRs within the next fifty years. Thus a prudent policy will take into account that depletion of uranium resources will not occur suddenly. As low-cost resources become scarce, the price of uranium may eventually rise to a level that may make the use of FBRs an economic proposition. Uranium resources are likely to be available in sufficient quantity for a transitional period until FBRs replace current types of nuclear reactors. Because of the long lead times of nuclear plant construction, the demand for uranium two to three decades ahead can be fairly easily assessed. The penalties for missing the right time for a transition to FBRs by a decade or two is rather small, as the cost of natural uranium accounts for less than 10 per cent of the total electricity costs in LWRs.

Once reprocessing is available on a larger scale, advanced core designs may become feasible for the LWR that greatly enhance its fuel efficiency. A study by Kraftwerk Union and the Karlsruhe laboratory, for example, proposed a core that uses five times less fuel than present designs. If such designs have lower electricity costs than FBRs, they may delay the need for FBR commercialization by decades.

Premature construction of an uneconomical FBR demonstration plant may also be advocated as an insurance against short-term interruptions of uranium supply. However, one FBR demonstration plant alone would make a negligible contribution, and construction of a series of uneconomical FBRs may provide the desired insurance at a much higher price than other options. A fully developed LWR fuel cycle is little affected by interruptions of two or three years. Longterm supply-contracts can greatly increase the reliability of the international uranium trade. If additional insurance is desired, stockpiling and preparations for emergency mining of low-grade domestic ores or for extracting uranium from seawater may be less expensive options than a series of uneconomical FBRs. Once the technical feasibility of advanced LWR cores is demonstrated and reprocessing is available on a larger scale, this technology will be a strategy, as virtually no insurance premium cost will have to be paid against the threat of a uranium shortage.

\section{Economic uncertainties}

The perspective that the SNR-300 throws on FBR electricity costs suggests that economic uncertainties are several and large. According to the latest estimate in February 1981, the SNR-300 costs about seven times more per kilowatt of net electric output than a commercial LWR, which was offered at that time at a price of about DM 2,550 (£540) per kilowatt (including owner's cost, but excluding the first core and the interest, inflation and taxes during construction). Scaling-up to sizes around 1,300 megawatt would reduce the cost per kilowatt of the breeder by 40-60 per cent. But this would still imply FBR capital costs 2.7 to 4.3 times greater than LWR costs.

The firms constructing the SNR-300, nevertheless, argue that this plant may not be representative of future large FBRs. In particular they say that:

- The cost includes a good dcal of research and development that will not have to be repeated for future plants. 
- The SNR-300 design is sub-optimal with regard to cost, since design changes imposed by the licensing authorities had to be incorporated into a largely fixed plant concept.

- The supplier's engineering capacity was underutilized as it could not be deployed for other projects during the construction delays caused by the licensing procedure.

These arguments suggest that by extrapolating from the SNR-300 data we may overstate the construction cost of future large FBRs. But we do not know by how much. If engineering services are excluded from the SNR-300 cost estimate, my calculation still suggests FBR capital costs at least double those of the LWR. On the other hand, the costs of SNR-300 are bound to increase further before the plant is completed. As for the next few large FBRs, it is highly probable that most of the factors that have increased the cost of the SNR-300 will still apply, although perhaps to a lesser extent. These factors will become insignificant only if a series of nearly identical plants is constructed at the rate of about one a year.

The hopes of the FBR community now rest on the French 1,200 megawatt SuperPhénix, which costs about twice as much as a French LWR plant of the same size. FBR advocates expect that cost-saving design changes, a relaxation of safety requirements and series production will help reduce construction costs. However, experience with the LWR suggests that it is not certain that cost savings through learning and series production will be quickly achieved. LWR costs have increased dramatically over the past decade. The effects of learning and series production have been cancelled out by other factors such as changes in licensing requirements, increasing quality assurance and control, and schedule slippages.

Estimated fuel-cycle costs for the SNR-300 are so high that the plant would not be commercially competitive even with nil investment costs. According to a forecast in 1973 by the utilities owning and operating the plant, operating costs will be such that the net returns from the sale of electricity are just about enough to pay usual depreciation and interest on a capital investment of DM 100 million. This is less than the amount to be invested in the reactor core (fabrication and plutonium), which for the SNR-300 is paid for by the state, but in commercial operation would have to be financed as a fixed cost by the utilities.

Over the past few years, the cost estimates for the SNR-300 fuel-cycle have become even more unfavourable. Fuelfabrication costs have doubled in constant prices, while the fabrication costs of uranium fuel for LWRs have decreased in real terms. Thus the fuel-fabrication for the SNR-300 is now estimated to cost about thirty times more than for LWR fuel. The original estimate for reprocessing excluded the capital cost of the reprocessing facility.
It was based on the assumption that the fuel of the SNR-300 would be reprocessed in the West German WAK plant, but included no allowance for the construction cost of this facility or for the costs of its adaptation for FBR fuel. When exploring the possibility of reprocessing the SNR-300 fuel in foreign reprocessing facilities, the utility operating the SNR-300 received quotes that indicated much higher costs.

The dismally-high cost estimates for the SNR-300 are partly the result of the small scale on which the fuel cycle for this plant operates. But they also reflect soaring cost estimates for reprocessing of spent fuel and for fabrication of plutonium fuel in general. Because of its toxicity, plutonium fuel has to be fabricated in special plants. These plants can also fabricate plutonium fuel for LWRs. But at present they are still at a pilot or prototype scale.

Recprocessing facilities for LWR or advanced gas-cooled reactor (AGR) fuel can accommodate a few FBR fuel elements if these are reprocessed together with a larger number of LWR or AGR fuel elements. As long as the FBR capacity in operation is small compared with that of the LWRs or AGRs installed, this may be sufficient. Because FBR fuel has a higher plutonium content, generates more decay heat and contains more radioactive fission products than AGR or LWR fuel, the large-scale use of FBRs will, however, require either the modification of reprocessing facilities which were designed for AGR or LWR fuel or the construction of special facilities for FBR fuel.

Over the past decade, cost estimates for reprocessing of spent fuel and plutonium recycle have increased to a level that makes such operations commercially unattractive for LWRs at present uranium prices. The uncertainty persisting in these cost estimates is highlighted by the fact that present contracts with British and French reprocessors have basically a cost plus fixed-fee price. The cost of reprocessing will be known with some certainty only after the French and British have begun operating their large reprocessing facilities for oxide fuel now being constructed and when plutonium recycling is possible within a truly commercial framework.

Even then, however, some cost uncertainties will remain for the FBR fuelcycle, because its technology differs from the plutonium fuel-cycle for LWRs. One such difference concerns cooling time. If spent fuel is stored before reprocessing, its decay heat and radioactivity decreases, so that reprocessing can cost less. The West German reprocessing plant for LWR fuel planned for a site in Hessen is intended for fuel with a cooling time of seven years. Shorter cooling times are essential for FBRs, to make effective use of their potential to breed new fuel and to reduce the financial charges on the fuel bound up in the fuel cycle. It may be technically possible to achieve the desired short cooling time, but it is not yet known what engineering efforts will be necessary and what impact this will have on reprocessing cost. There is a real possibility that these economic uncertainties may come out unfavourably and that a very large increase in the price of uranium may be required to make the electricity costs of the FBR competitive with those of the LWR. This would delay FBR commercialization by several decades or more. In such an event construction and operation of a demonstration plant would require a large subsidy while the demonstrated technology would become obsolete before a larger number of FBRs are constructed.

\section{Time-risk trade-off}

Construction of a large FBR demonstration plant in the next ten years or so thus reduces only one of several key uncertainties. It will tell us nothing about the future growth of nuclear power or the availability of uranium; and it decreases only a little the uncertainty about fuel fabrication and reprocessing costs, as these services then will still have to be operated on a small scale.

On the other hand, no matter whether a large FBR demonstration plant is constructed or not, every year that passes gives us more information on future demand for nuclear power and the availability of uranium. And if we wait until rising uranium prices make plutonium recycling a commercially viable operation for LWRs, we shall have a much better basis to assess the economics of the FBR fuel cycle. Yet this may take a very long time if long-term storage of spent fuel proves environmentally as acceptable as fuel reprocessing, and the near-term future of nuclear power is based on LWRs operated in a once-through mode without reprocessing. But the rewards of waiting will be great in terms of reduced economic uncertainties.

As the fuel-cycle facilities of the FBR build on technologies of the LWR fuel cycle, there is a clear case of a time-risk trade-off. Constructing an FBR demonstration plant in the next ten years or so will involve much higher technical and commercial risks than doing the same thing later. And the analysis of uranium supply and demand suggests that there is no commensurable benefit to the public from taking the high risk now rather than taking the much lower risk later. If an FBR demonstration plant has higher costs than utilities are willing to pay, and if risksharing by the government is not sufficient to bring the commercial risk down to a level acceptable to the utilities, subsidies from the taxpayers' purse would be used only to take an unnecessary risk. In such a situation, the short-term calculations of utilities are likely to lead to a decision that is consistent with the public's long-term interest.

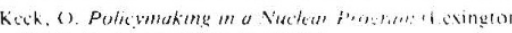
Books, Lesington. Kentuckt, 1981.)

Eads, (i. \& Nison, R. Public Policy 19, $\$ 05-\$ 27$ (1971)
} 